\section{Pyruvatkinase, in Erythrozyten}

H. Baum

Institut für Laboratoriumsmedizin, Mikrobiologie und Blutdepot, Regionale Kliniken Holding RKH GmbH, Ludwigsburg, Deutschland

Englischer Begriff pyruvate kinase; erythrocytes

Definition Enzym, das die Konversion von Phosphoenolpyruvat zu Pyruvat katalysiert.

Beschreibung Die Pyruvatkinase ist ein Enzym der anaeroben Glykolyse und katalysiert die Reaktion von 2-Phosphoenolpyruvat zu Pyruvat unter Übertragung der Phosphatgruppe auf ein ADP und Bildung von ATP. Das Enzym existiert in insgesamt 4 Isoformen, wobei die Isoform PK-R in Erythrozyten vorkommt. Mutationen im PK-R-Gen, die mit einer verminderten Aktivität des Enzyms in den Erythro- zyten einhergehen, führen $\mathrm{zu}$ hereditären nichtsphärozytischen hämolytischen Anämien. Es sind bis heute mehr als 100 verschiedene Mutationen im PK-Gen gefunden worden, wobei nur doppelt heterozygote oder homozygote Merkmalsträger klinische Symptome zeigen. Dabei ist der genaue Mechanismus, der schließlich zur Hämolyse führt, noch nicht aufgeklärt.

Die Diagnose führt über die Bestimmung der Enzymaktivität in den Erythrozyten, wobei meist Aktivitäten zwischen 5-40 \% der normalen Enzymaktivität gefunden werden. Die normale PK-R-Aktivität beträgt 20,2 $\pm 2,2 \mu$ mol Substratumsatz/g Hb/min. Im antikoagulierten Blut ist der Parameter bei $+4{ }^{\circ} \mathrm{C} 1$ Woche stabil, nach Präparation des Hämolysates muss dieses jedoch sofort analysiert werden.

\section{Literatur}

Zanella A (2000) Red cell pyruvate kinase deficiency: from genetics to clinical manifestation. Baillieres Clin Haematol 13:57-81 